Proceedings of the WELCOME Scientific Meeting on Hybrid Nanostructures, Toruń, Poland, August 28-31, 2011

\title{
AFM Investigation of Biological Nanostructures
}

\author{
J. Strzelecki ${ }^{a, *}$, M. DąBrowski ${ }^{a}$, J. StrzeleckA ${ }^{b}$, M. Tszydel $^{c}$, K. Mikulska $^{a}$,
} W. NOWAK ${ }^{a}$ AND A. BALTER ${ }^{a}$

${ }^{a}$ Institute of Physics, Nicolaus Copernicus University, Grudziądzka 5, 87-100 Toruń, Poland

${ }^{b}$ Medical Physics Department, Oncology Center, I. Romanowskiej 2, 85-796 Bydgoszcz, Poland

${ }^{c}$ Department of Ecology and Vertebrate Zoology, University of Łódź, S. Banacha 12/16, 90-237 Łódź, Poland

Nanostructures created by living organisms, optimized through millions of years of evolution, can be a valuable inspiration for nanotechnology. We employ atomic force microscopy to examine such structures in materials created by common organisms - caddisfly and diatoms. Caddisfly larvae are well known for their ability to spin silk, which serves as an "adhesive tape" to glue various materials and collect food in aqueous environment. Atomic force microscopy imaging of caddisfly silk, performed for the first time by our team, has shown that its surface is patterned with $150 \mathrm{~nm}$ extensions - a feature related to its exceptional underwater sticking abilities. Results of force spectroscopy of protein structures found on the surface are also shown. A characteristic feature of diatoms is that they are encased within a unique silica cell wall called frustules, patterned with $200 \mathrm{~nm}$ pores, which allow cellular interaction with the environment. We perform atomic force microscopy imaging of frustules in living diatoms as well as adhesion measurements inside pores.

PACS: 87.64.Dz, 81.07.-b

\section{Introduction}

Nanostructures created by living organisms, optimized through millions of years of evolution, can be a valuable inspiration for nanotechnology [1]. Exceptional mechanical properties of complex, hierarchical structures found in living organisms can be achieved with commonly found materials, as was already shown in studies of gecko feet [2], lotus effect [3] and spiderweb [4].

Atomic force microscopy (AFM) is an ideally suited tool for investigation of such objects. It has a superb resolution and allows measurements in liquid environments. It also has the ability to evaluate mechanical properties of materials, either by nanoindentation [5] or stretching of single biomolecules [6] and small structures [7, 8]. In our paper we show how this tool can be used to study nanostructures found in caddisfly silk and diatom frustule.

Silks made by silkworms and spiders have already gained much interest, both as fibers with exceptional properties [9], but also as biomaterials [10]. Their performance, however, is strongly influenced by water [11]. Caddisfly (Trichoptera) larvae (Fig. 1A) have a caterpillar shape and occur in all types of fresh water and marine environments while the adults (imagines) are terrestrial and look much like drab, fragile moths, often occurring in large numbers in lakeside or streamside habitats. The larvae of all Trichoptera species are capable of making floss owing to their symmetric twin spinning glands, i.e. transformed salivary glands. The semi-fluid liquid secreted from spinning glands is solidified in water to form a strong and elastic thread used for shelter construction and to catch food. To perform those tasks, the caddisfly silk has to be hardly soluble in water. Thus, it can pro-

\footnotetext{
* corresponding author; e-mail: jast@fizyka.umk.pl
}

vide a material for fibers excelling in underwater tasks, with a possible biomaterial application [12]. Since the silk is used by the insects as a water-resistant "adhesive tape", its closer inspection can further develop the glue working in wet conditions [13]. Only very limited AFM examination of caddisfly silk was done so far [14, 15].
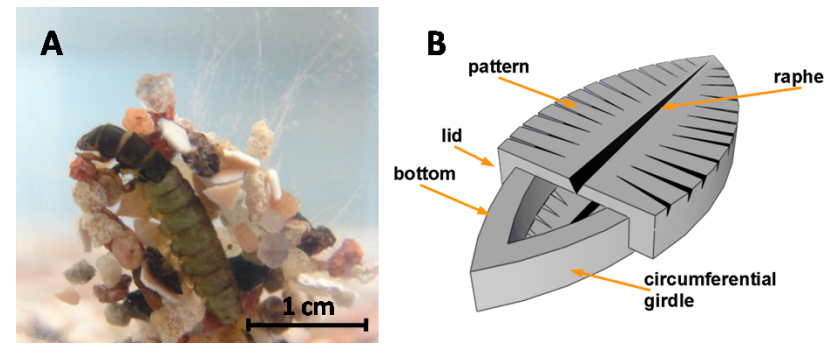

Fig. 1. Caddisfly larvae (A, Hydropsyche angustipennis, photo by M. Tszydel) use silk fibers as an "adhesive tape" to construct a protective shelter and catch food. Unicellular diatoms (B, schematic picture) are encased in a silica "box" called frustule, patterned with pores allowing for interaction with the environment and a raphe to excrete mucilage.

Diatoms (Bacillariophyceae) are a diverse group of unicellular algae, with more than 10000 species identified [16]. Their characteristic feature is the amorphous silica cell wall called frustule (Fig. 1B). This exoskeleton, formed by two fitting halves, can adapt a huge variety of shapes and sizes. The frustule is also spectacularly patterned, both in micro and nanoscale, with ornaments specific to each species. This ornament is mainly formed by tiny pores that allow cellular interaction with the environment. The ability to form very complicated, repetitive $3 \mathrm{D}$ silica structures at small scale makes those organisms a very interesting subject for nanotechnology 
research [17]. Additionally, diatoms, similarly to other algae, can attach to various surfaces in water environment, using excreted mucilage as glue. Thus, similarly to caddisfly, its research can further develop the biocompatible, water-resistant adhesive, that can possibly replace use of sutures [18].

Although scanning electron microscopy and optical microscopy are most frequently used for diatom research, hard silica surface makes diatoms a relatively easy target for AFM examination [19]. In particular, species that attach to substrates can be easily imaged alive under ambient conditions, with minimal sample preparation [20]. Nanomechanical measurements of frustules were also performed with nanoindentation [21]. Force spectroscopy of mucilage has led to discovery of force curves with repetitive, saw-like patterns similar to those found for modular proteins [22].

\section{Materials and methods \\ 2.1. Trichoptera}

The material consisted of the floss produced by caddisflies of the species Hydropsyche angustipennis. The fibres were obtained from laboratory-bred larvae in the most advanced developmental stage (the 5th larval instar). In the laboratory, each of the specimens was reared separately in a plastic box (500 $\mathrm{ml}$ in capacity) filled up with fresh water. In order to eliminate pollution of fibres with the products of metabolic transformations, caddisflies larvae were deprived of nourishment. Collected silk was untangled with a sharp needle to isolate single fibers. Straightened fiber was glued to a glass substrate with nail polish. An AFM contact mode imaging of dry fibers was performed using Bioscope 2 Bruker (former Veeco) AFM, with MSNL-D probes. Force spectroscopy measurements were conducted in deionized water using a homemade AFM inspired by the design described in [23]. A MSNL-C cantilever was calibrated using the thermal tune method [24], placed over fiber using an inverted optical microscope and lowered on its surface with a micrometer screw. After touching the surface, a piezostack moved the cantilever away and towards the sample within the limit of $15 \mu \mathrm{m}$. Silk structures were picked by the untreated cantilever tip and stretched at $400 \mathrm{~nm} / \mathrm{s}$ with a 2-4 $\mathrm{nN}$ loading force.

\subsection{Diatoms}

Sample preparation followed the protocol published in [20]. Diatoms of type Cocconeis placentula (Ehrenberg) and Cocconeis placentula varietas euglypta (Ehrenberg) were laboratory bred in an aquarium with water samples collected from Przysiek water reservoirs near Torun. Microscope slides were left in the aquarium for two days, allowing diatom attachment at the surface. Afterwards, the slides were rinsed with deionized water and mounted on the AFM stage. An optical microscope was used to select living diatoms for measurements. Both contact mode imaging and force spectroscopy were performed with a Bioscope 2 AFM.

\section{Results and discussion}

\subsection{Trichoptera}

AFM images in contact mode show that the silk surface is uneven and densely covered with numerous $150 \mathrm{~nm}$ projections. This result agrees with our earlier observations [14]. A recent report [15] confirms this findings, and indicates that the patterning is a result of nanofibrillar structure of silk. Similar surface pattern and fibrillar structure were also observed in silkworm silk [25] and spider silk [26]. Presence of this nanostructural pattern can enhance the performance of Trichoptera silk as an "adhesive tape". Silk surface is thus more capable to adhere to various materials through increased surface contact area.

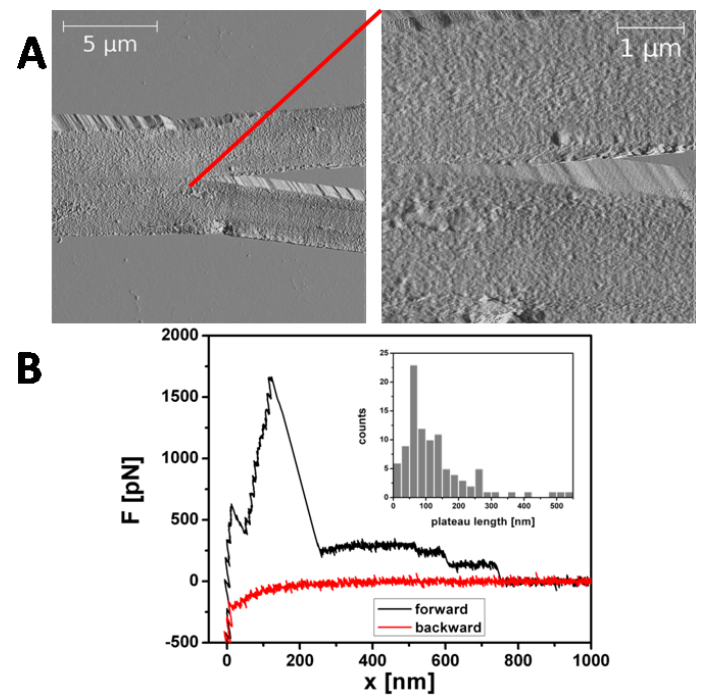

Fig. 2. AFM contact mode imaging (deflection error) and force spectroscopy of Trichoptera silk. Large scale imaging shows that silk floss consists of two joined ribbons. The silk surface is covered with $150 \mathrm{~nm}$ size bumps, which reflect complex internal structure (A). Force spectroscopy at the silk surface shows curves associated typically with unpeeling of structures from the surface (B). The inset presents a distribution of unpeeling plateaus.

Force spectroscopy performed at silk surface resulted in a diverse range of force curves, with saw-like force curves more extensively described in our previous work [14]. Here we analyze step-like curves (Fig. 2B), combined with a strong adhesion. Curves of this kind are typically associated with unpeeling of polymers or fibers [7, 27]. When segments of stretched object detach from the surface, plateaus of corresponding lengths appear in force curve. A distribution of measured lengths of unpeeling steps (Fig. 2B inset) indicates an approximate detachment of $75 \mathrm{~nm}$. This observation suggests the existence of adherent and easily desorbed nanofibers at the silk surface. 


\subsection{Diatoms}

Hard surface of silica frustules of living diatoms was imaged under ambient conditions in high detail (Fig. 3A). Differences in pattern between Cocconeis placentula (lower right) and Cocconeis placentula varietas euglypta (center) can be easily seen. Magnification shows further details of pores. Since AFM closed loop imaging allows to obtain very accurate sample topography, measurements of frustules dimensions can be made. The depth of AFM tip penetration into the pores for Cocconeis placentula was within the $2-11 \mathrm{~nm}$ range, while in the case of wider pores of Cocconeis placentula var. euglypta it was in the $7-42 \mathrm{~nm}$ range. The average mutual separation of pores was $514 \pm 239 \mathrm{~nm}$ for Cocconeis placentula and $427 \pm 73 \mathrm{~nm}$ for Cocconeis placentula var. euglypta.

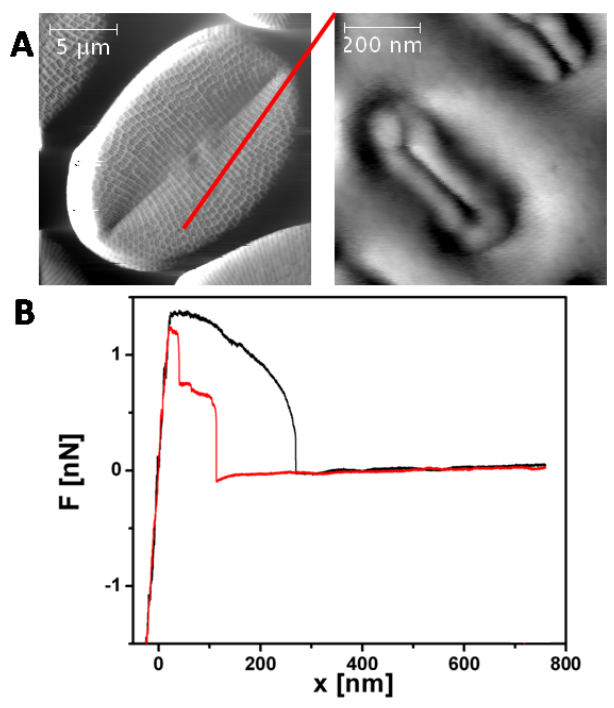

Fig. 3. AFM contact mode imaging and force spectroscopy of diatomic frustules surface. AFM imaging (contact mode, deflection error) can be used to directly visualize and measure the surface features of frustules (A). Force spectroscopy in pores (B) shows a force curve with the extended adhesion and step-like pattern of attractive force.

We also performed force spectroscopy measurements inside the pores (Fig. 3B). Force curves obtained showed the extended adhesion peak, with forces at approximately $1.5 \mathrm{nN}$ and average range of $304 \mathrm{~nm}$. A step-like change in the attractive force was also observed, a feature which typically is not present. Adhesion forces observed in raphe region showed a distinguishably shorter range of $114 \mathrm{~nm}$, while the force remained similar. Further experiments are in preparation to provide a better understanding of this behavior.

\section{Conclusions}

We performed AFM investigations of nanostructures found at the surface of constructs created by two commonly met organisms - caddisfly and diatoms. Atomic force microscopy allowed us to obtain data that are beyond reach of methods typically used in biology. Both organisms employ material engineering at nanoscale, which yields exceptional performance, vital for their evolutionary success.

\section{Acknowledgments}

J.W. Strzelecki acknowledges Faculty of Physics, Astronomy and Informatics grant for young scientists. J.W. Strzelecki and J. Strzelecka acknowledge "Krok w Przyszlosc" Edition I (JWS, JS), II (JS) \& III (JWS) from Kuiavian-Pomeranian Voivodeship and EU.M. Tszydel acknowledges research grant of Polish Ministry of Science and Higher Education "Iuventus Plus".

\section{References}

[1] B. Bhushan, Philos. Trans. R. Soc. A, Math. Phys. Eng. Sci. 367, 1445 (2009).

[2] H. Gao, X. Wang, H. Yao, S. Gorb, E. Arzt, Mech. Mater. 37, 275 (2005).

[3] Y.T. Cheng, D. Rodak, C. Wong, C. Hayden, Nanotechnology 17, 1359 (2006).

[4] N. Becker, E. Oroudjev, S. Mutz, J. Cleveland, P. Hansma, C. Hayashi, D. Makarov, H. Hansma, $\mathrm{Na}$ ture Mater. 2, 278 (2003).

[5] M. Lekka, P. Laidler, D. Gil, J. Lekki, Z. Stachura A. Hrynkiewicz, Europ. Biophys. J. 28, 312 (1999).

[6] T.E. Fisher, P.E. Marszalek, J.M. Fernandez, Nature Struct. Biol. 7, 719 (2000).

[7] M. Kellermayer, L. Grama, A. Karsai, A. Nagy, A. Kahn, Z. Datki, B. Penke, J. Biol. Chem. 280, 8464 (2005).

[8] M. Benoit, D. Gabriel, G. Gerisch, H. Gaub, Nature Cell Biol. 2, 313 (2000).

[9] C. Stevens, Industrial Applications of Natural Fibres: Structure, Properties and Technical Applications, Wiley, Chippenham 2010.

[10] D. Porter, F. Vollrath, Adv. Mater. 21, 487 (2009).

[11] C. Mo, P. Wu, X. Chen, Z. Shao, Vibrat. Spectrosc. 51, 105 (2009).

[12] J. Bilska, I. Krucinska, Fibres Textil. East. Eur. 13, 54 (2005).

[13] R. Stewart, C. Wang, Biomacromolecules 11, 969 (2010).

[14] J.W. Strzelecki, J. Strzelecka, K. Mikulska, M. Tszydel, A. Balter, W. Nowak, Centr. Europ. J. Phys. 9, 482 (2010).

[15] N.N. Ashton, D.S. Taggart, R.J. Stewart, Biopolymers, DOI: 10.1002/bip.21720, 2011.

[16] F.E. Round, R.M. Crawford, D.G. Mann, The Diatoms: Biology and Morphology of the Genera, Cambridge University Press, Bath 1990.

[17] R.W. Drum, R. Gordon, Trends Biotechnol. 21, 325 (2003).

[18] A.S. Mostaert, C. Giordani, R. Crockett, U. Karsten, R. Schumann, S.P. Jarvis, J. Adhesion 85, 465 (2009). 
[19] S.A. Crawford, M.J. Higgins, P. Mulvaney, R. Wetherbee, J. Phycol. 37, 543 (2001).

[20] I.C. Gebeshuber, , J. Kindt, J. Thompson, Y. Del Amo, H. Stachelberger, M. Brzezinski, G. Stucky, D. Morse, P. Hansma, J. Microsc. 212, 292 (2003).

[21] N. Almqvist, Y. Delamo, B.L. Smith, N.H. Thomson, A. Bartholdson, R. Lal, M. Brzezinski, P.K. Hansma, J. Microsc. 202, 518 (2001).

[22] T. Dugdale, R. Dagastine, A. Chiovitti, P. Mulvaney, R. Wetherbee, Biophys. J. 89, 4252 (2005).

[23] F. Kühner, R. Lugmaier, S. Mihatsch, H. Gaub, Rev. Sci. Instrum. 78, 75105 (2007).
[24] J. Hutter, J. Bechhoefer, Rev. Sci. Instrum. 64, 1868 (1993).

[25] S. Putthanarat, N. Stribeck, S. Fossey, R. Eby, W. Adams, Polymer 41, 7735 (2000).

[26] S. Gould, K. Tran, J. Spagna, A. Moore, J. Shulman, Int. J. Biol. Macromol. 24, 151 (1999).

[27] D.B. Staple, M. Geisler, T. Hugel, L. Kreplak, H.J. Kreuzer, New J. Phys. 13, 013025 (2011). 